DIGITALCOMMONS

—@WAYNESTATE —
Michigan Journal of Counseling:

Research, Theory and Practice

$3-1-2011$

\title{
Multicultural Counselor Competency in College Counseling Centers: Recommendations for Implementation
}

Chris Cubero

Slippery Rock University Counseling Center, chris.cubero@sru.edu

Follow this and additional works at: https://digitalcommons.wayne.edu/mijoc

\section{Recommended Citation}

Cubero, C. (2011). Multicultural Counselor Competency in College Counseling Centers: Recommendations for Implementation, Michigan Journal of Counseling, 38(1), 33-44. doi:10.22237/mijoc/1298937780

This Article is brought to you for free and open access by the Open Access Journals at DigitalCommons@WayneState. It has been accepted for inclusion in Michigan Journal of Counseling: Research, Theory and Practice by an authorized editor of DigitalCommons@WayneState. 


\section{Multicultural Counselor Competency in College Counseling Centers:}

\section{Recommendations for Implementation}

\section{Chris Cubero, Ph.D.}

Slippery Rock University

\section{Counseling Center}

\section{Abstract}

A brief review of the research on multicultural counselor competence is presented as well as a review of the measurement of self-reported multicultural counselor competence with suggested measurement instruments. Recommendations for the implementation of multicultural-specific training in college counseling centers are made through the use of an example program located in a northeastern public university counseling center. Program implementation recommendations and implementation based on International Association of Counseling Services standards are discussed. Concluding remarks and future research directions specific to college counseling center multicultural counseling programming are also included.

\section{Multicultural Counseling Competency in College Counseling Centers: Recommendations for Implementation}

By necessity, counseling professionals are challenged with meeting the service needs of individuals from diverse groups. To answer the challenge, counselor education programs along with their accrediting bodies are increasingly more aware of the importance of cultural differences in counseling practices. The standards of practice outlined by the Council for Accreditation of Counseling and Related Educational Programs (CACREP) include updated information on social and cultural diversity that parallel current research (CACREP, 2009). The International Association of Counseling Services (IACS, 2010) also recognized the importance of multicultural counseling competence in the role of counselors/counselors-in-training working within college and university settings. Thus, solidified counselor-in-training multicultural counseling awareness and knowledge of self and others, and skills when working cross-culturally are of the utmost importance.

The purpose of this article is to recommend ways to implement evidence-based multicultural counseling competency standards for counselors-intraining working as interns or practicum students in university counseling centers. To do so, the article describes a current college counseling center Alcohol and Other Drug (AOD) program's procedures and methods for training and measuring counselor-in-training multicultural counseling competency. Before-

Chris Cubero is an Assistant Professor \& Counselor in the Student Counseling Center at Slippery Rock University. He is also the Program Director of the Alcohol \& Other Drug . He can be reached at chris.cubero@sru.edu. 
hand, a brief review of the multicultural counseling competency research is provided that includes a review of common instruments of self-reported multicultural counselor competence (MCC). Self-reported MCC instruments can be utilized by counseling center programs to measure counselor-in-training multicultural counseling learning outcomes. Recommendations are outlined for the implementation of MCC standards into college counseling centers that can be utilized with on-site counselors-in-training. The article concludes with a discussion on meeting college counseling center standards of practice, future research, and new directions in multicultural counseling.

\section{Multicultural Counseling and Counselors-in-Training}

Sue et al.'s (1982) work provided the basis for MCC through the use of a three factor model (i.e. self-assessed attitudes/beliefs, knowledge of populations diverse from self, and the skills necessary to work with people diverse from our selves). First, counselor awareness of attitudes/beliefs toward their own race, ethnicity, and/or cultural heritage and their beliefs/attitudes toward the race, ethnicity, and cultural heritage of others is one factor in MCC. Second, counselor multicultural knowledge is generally defined as an understanding of the world-views of communities and the individuals within diverse communities. Third, multicultural counselor competence in terms of skills involves counselors' ability to use culturally sensitive interventions and strategies when working with clients from diverse backgrounds. The three factor model was embraced in whole or in part by counseling fields and has become a guide to the counseling education standardization bodies (e.g. CACREP, 2009). Thus, the definitions that guide counselor competence also guide how counselors-in-training are educated.

\section{Multicultural Counseling Competency}

The three factor model helped to define multicultural counseling competency (MCC). Pope-Davis, Liu, Toporek, and Brittan-Powell (2001) stated that MCC is guided by the three-factor model (awareness of attitudes/beliefs, knowledge, and skills) introduced by Sue et al. (1982). As suggested by Middleton et al. (2000) counselor-in-training MCC should include: (a) examination of their cultural values to see how they impact their cultural biases, (b) recognition of the impact of the counselor's own cultural values on diverse populations, and (c) acknowledgment of the differences that occur between diverse populations. MCC standards have also been established for counselor education programs including rehabilitation counselor education programs (Council for Rehabilitation Education; CORE, 2008) and programs falling under CACREP accreditation standards. The MCC standards embraced by CACREP and CORE are supported by IACS accreditation standards that encourage university counselors and trainees to have the appropriate levels of multicultural counseling competence. Overall, enhanced MCC occurs when counselors-in-training move toward more awareness of themselves in terms of cultural background, the cultures of others, and how these values impact their work with clients from diverse populations. 


\section{Multicultural Counseling Competency Instruments}

Instruments that measure self-reported MCC have put continued emphasis on the importance of effective multicultural counseling. The instruments also built upon the three-factor model of multicultural counseling (Arredondo \& Toporek, 2004). The three MCC instruments that have arguably received the most research attention are: (a) the Multicultural Counseling Knowledge and Awareness Scale (MCKAS; Ponterotto, Rieger, Barrett, \& Sparks, 1994), (b) the Multicultural Counseling Inventory (MCl; Sodowsky, Taffe, Gutkin \& Wise, 1994), and (c) the Multicultural Awareness Knowledge, and Skills Survey (MAKSS; D' Andrea, Daniels, \& Heck, 1991). Each instrument measures MCC differently and through research comparing all three each were found to be valid and reliable measures of MCC (Constantine, Gloria, \& Ladany, 2002; Constantine \& Ladany, 2001; Kocarek, Talbot, Batka, \& Anderson, 2001; Pope-Davis \& Dings, 1994). The MCAS measures two factors (awareness of beliefs/attitudes and knowledge), the $\mathrm{MCl}$ measures 4 factors (awareness of beliefs/attitudes, knowledge, skills, and the multicultural counseling relationship), and the MAKSS, the most congruent with the original three-factor model, measures 3 factors (awareness of beliefs/attitudes, knowledge, and skills). The slight variations in MCC instrumentation help to complement the various purposes of individual counseling center programs. For example, a counseling program with an objective to measure of cross-cultural counseling relationships of its counselorsin-training may benefit more from the use of the $\mathrm{MCl}$ with its built-in multicultural counseling relationship scale.

\section{Multicultural Counselor Competency in a College Counseling Center}

The following section describes a northeastern university counseling center Alcohol and Other Drug (AOD) program that has implemented counselorin-training multicultural counseling competence training and evaluation. The integration of multicultural counseling training and evaluation was encouraged by accreditation standards that stipulated "counseling services must provide counseling interventions that are responsive to the diverse population of students..." (IACS, 2010, p. 3), and "there must be regular review of the counseling service based on data from center evaluation efforts" (p. 5). The counseling center that contains the AOD program has since earned its accreditation through IACS. After a brief program description, recommendations for the implementation of MCC counselor-in-training preparation and evaluation follow based on the AOD Program's efforts.

\section{Program Description}

A specific aim of the AOD education program is to screen AOD use risk in students who violate the university's code of conduct for AOD-related offenses. Screenings, or interviews, are performed by graduate-level students recruited from the university Counseling and Development graduate program and scheduled through the university counseling center. Once AOD use risk levels are determined by the graduate-level interviewers, student-code of conduct violators receive a follow up feedback meeting with the same interviewer and are referred to appropriate levels of prevention education. 
The AOD program has a 5-year history of recruiting graduate students to perform interviews and feedback meetings. Typically, recruited students are drawn from the Community and Addiction Counseling program track in the master's-level program of study. To broaden the graduate students' skills, on-site training is provided at the beginning of fall and spring semesters. The training traditionally consisted of education in: (a) interviewing; (b) providing feedback, and (c) determining appropriate levels of education. Interview and feedback meeting role plays are provided during the trainings by the AOD program onsite director. In addition to a certified training (students receive a certificate) in the use and scoring of the Substance Abuse Subtle Screening Inventory (SASSI; Miller, 1985), the graduate students are trained to provide comprehensive interviews that consider life domains that can impact AOD use risk. The domains include a family history of AOD use, current use of medications, and past AOD related legal concerns to name a few. Graduate student interviewers use results from the SASSI and their interview to determine student code of conduct violators' levels of risk-related prevention education. Those with low AOD-related risk are deemed completed after the feedback meeting. However, other student-violators are referred to either one 90-minute education group or three 90-minute education groups based on their level of AOD-related risk. Recently, strategic planning to improve on the AOD program and IACS accreditation led to the implementation of additional interviewer (i.e. graduate-level students) training and evaluation in MCC.

\section{Implementation Recommendations}

Addressing multicultural counseling effectiveness is essential to counselor-in-training development. Competency in multicultural counseling requires that counselors-in-training remain open to their biases toward others and to the specifics of their own cultural heritage. In so doing, they can begin to acknowledge the need to recognize the cultural needs of themselves and the people they serve. Seven recommendations are described below to assist counselors-in-training (i.e. trainees) programmatically and have been implemented by the on-site supervisor/AOD program director at the current university counseling center.

1. A training session at the beginning of the school year (i.e. fall semester) is recommended to introduce counselors-in-training to the need to perform cross-cultural interviews, assessment, and/or counseling. Trainees are introduced to the importance of cross-cultural interactions by the site supervisor (i.e. AOD program director) and are subsequently aware that cross-cultural counseling is a key part of their work at the center. Introducing the dialogue of crosscultural interactions early normalizes the need for effective multicultural counseling. Thus, trainees learn that they have a forum for discussions of a multicultural counseling nature in group supervision/training and if possible individually.

2. Provide trainees with evidence-based material on effective multicultural counseling. The current program uses a power-point presentation with the following headings: (a) Factors of Effective Counseling, (b) Multicultural Awareness, (c) Multicultural Knowledge, (d) Multicultural Skills, and (e) Critical Incidents. Included in the power-point presentation is an activity that provides train- 
ees with case examples that they are encouraged to discuss among other trainees. An example case includes questions like: "What awareness, knowledge, and skills would assist in interviewing a person who uses a wheelchair?" Thus, the trainees learn what it means to have multicultural awareness, knowledge and skills and recognize the importance of effective interviewing that is culturally -relevant.

3. As supervisors, being available to counselors-in-training on a one-on-one basis is vital. Group trainings and group supervision may be utilized to train in concerns that may arise in cross-cultural interactions, however some trainees may express themselves more effectively and comfortably in one-on-one supervision. This is especially true if a trainee requires support in their recognition of a personal bias toward a particular person or group. Supervision can assist trainees with facing, accepting and if necessary modifying their biases. Supervisors should be in a position to make referrals to other professionals (e.g. university counselor) if it is deemed that trainees might benefit from exploring their biases more deeply or if their biases are impacting their effectiveness as a counselor-in-training.

4. A fourth recommendation is to utilize graduate students that have more training than other beginning counselors. The current AOD program recruits first and second-year graduate students to do interviews. Therefore, second-year trainees are encouraged during training sessions to model proper aspects of multicultural counseling to those who are new to the program. The peer to peer relationships developed through this process encourage cohesiveness amongst the group of trainees and provide new recruits with a broader resource base of information and guidance.

5. Provide training in interviewing that is holistic and culturally sound. Stated differently, trainees are encouraged to interview holistically with detail to the many domains of student-violators' histories as they relate to AOD-related concerns (discussed previously). Holistic interviews also require that trainees ask specific questions about the clients' experiences culturally including past discrimination, prejudice and/or critical incidents. An example question asked of student violators is: "Tell me about a time you were discriminated against because of your race, ethnicity, or sexual orientation." Recommending that trainees ask about past discrimination can lead to hesitation in trainees. However, trainees are encouraged to move toward these interviewing skills rather than away from them. The results of asking questions of a cultural nature can lead to clients being heard and recognized at a cultural level, which leads to more ethically sound interviewing.

6. Another recommendation is to facilitate multicultural-specific follow up training sessions. A training session at the beginning of the year, although helpful, does not create enough cohesiveness among the trainees. Follow up trainings (e.g. beginning of spring semester) allow supervisors to check in with trainees that may have needed less support throughout the year. In addition, bringing the trainees together gives the trainees a chance to exchange experiences and develop peer to peer relationships. Peer to peer relationships are fostered during the training sessions. Training session facilitation in multicultural counseling guides trainees to an exchange of ideas that is specific to the cultural, 
racial, ethnic needs of the students they interview. Trainees are facilitated through additional case examples (see recommendation \#5) and are encouraged to discuss the inevitable cross-cultural experiences they have had throughout the year within a Socratic seminar-type milieu.

A final recommendation is to utilize an evaluation tool that measures MCC. As discussed previously, certain instruments may be better suited to particular programs than others. The current program utilizes the MAKSS-CE-R skills scale (10 questions) to evaluate how competent in multicultural counseling trainees perceive themselves to be the end of the school year. On average evaluated trainees have rated themselves as above average in their self-reported MCC. Although not utilized by the current program, the use of a pre-post design where the MCC instrument is, for example, used once at the beginning of the school year and once at the end could provide for additional evaluative information for the program. In addition, pre-post evaluations and/or control group experiments (e.g. one group receives multicultural training and another does not) opens to the possibility for valuable research reporting.

\section{Summary}

\section{Multicultural Counseling Competency Training}

The goals of the multicultural counseling-based training sessions are to: (a) introduce first-year graduate student recruits to cross-cultural counseling interactions, (b) introduce recruits to the value of on-site supervision, and (c) establish a forum for second year recruits to provide peer mentoring in multicultural counseling. The objectives toward fulfilling these goals include mandatory training sessions at least twice during the school year, group and one-on-one on-site supervision, and evaluation of trainee MCC. The goals and objectives for the graduate-level trainees directly influence the mission of the AOD program to provide ethical counseling to the student-code of conduct violators that are served.

In sum, the first semester training session sets the stage for trainees to share their experiences in multicultural counseling throughout the rest of the year in subsequent training sessions, on-site supervisory interactions and peer to peer interactions. At the beginning of the second semester trainees receive additional instruction on interviewing, feedback and cross-cultural interactions. By the second semester all trainees have had a chance to do at least one interview and some had the opportunity to have interviews with student-interviewees from diverse groups. The training sessions are set up to invoke trainees' personal experiences as interviewers; therefore, the training discussions provide a more in-depth understanding of what it is like to work in cross-cultural interactions. Thus, additional time is allotted for processing of cross-cultural interactions and discussions of the connections between theory-based learning (i.e. learned in graduate coursework) of multicultural counseling and the applied use of multicultural-specific interviews among the trainees.

A secondary benefit of the training sessions is that the trainees receive group supervision, not only from the on-site faculty supervisor (i.e. AOD program director), but vicariously from students who have a previous year's experi- 
ence as interviewers. The group supervisory training interactions set the stage for later one-on-one supervision that is multicultural counseling specific. One-on -one supervision on-site occurs as needed and concerns specific to crosscultural counseling sessions are dealt with if applicable. Graduate student trainees are encouraged to be aware of what can occur during cross-cultural interactions and to voice any awareness of biases and/or attitudes they have about working with diverse groups. Trainee concerns can be brought directly to the AOD program director and/or their peers. Deeper concerns can be addressed through one-on-one site supervision, where referral resources may be utilized as needed.

Positive consequences of the AOD program's training sessions have emerged. First, trainees were able to identify with what it means to be a professional counselor. Trainees received a certification in the administration of the SASSI (Miller, 1985) and enhanced awareness, knowledge and skill in: (a) what it means to work with people who have indicated risk of AOD use and (b) performing interviews that recognize the multicultural needs of student-code of conduct violators. Second, the graduate-level trainees gained pre-practicum and pre-internship applied learning. Therefore, their transition to practicum and internship courses was eased. Trainees also had the opportunity to apply knowledge learned in the classroom to their experiences working as interviewers. Finally, the on-site AOD program work and training sessions subjected students to the importance of cross-cultural interactions that complements coursework knowledge gained. Stated differently, the recruited trainees gain awareness and knowledge of MCC from their academic program and learn MCC skills from their on-site experiences with the AOD program. Therefore, the AOD program's graduate student involvement is a collaborative effort in student learning invoking academic and practical educational settings.

\section{Multicultural Counseling Competence Evaluation}

The current AOD program utilizes the MAKSS-CE-R skills scale (Kim et al., 2003) to evaluate graduate-level trainee self-reported MCC levels. To date, results of MAKSS-CE-R are consistent with past research using the MAKSS-CE - $R$ with graduate-level counselors-in-training that found above average skill scale results (Cubero, 2009 \& Donnell, 2008). The above average MCC skill results may be a consequence of the training sessions as found previously (Pope-Davis \& Ottavi, 1994) and/or the on-site supervision as found previously (Constantine, 2001). Additional evidence of MCC skills could be obtained from further study. For example, a possible research methodology invoking a prepost design that uses the MAKSS-CE-R skills scale could show clearer evidence of the impact of supervision and/or training on counselor-in-training MCC.

\section{Program Standards for Implementation}

Not all college counseling centers are overseen by an accrediting body. However, accrediting bodies often strive to meet standards of practice for university counseling centers. For instance, IACS (2010) is an association that encourages college counseling centers to meet outlined professional standards of practice. In terms of multicultural competency within the role of counselor, IACS 
encourages that: (a) professional staff have previous supervised training, (b) training and supervision to counselors-in-training acknowledges the needs of diverse populations and (c) outreach programming to community recognizes the specific needs of diverse populations. Accreditation can therefore act as a guide and a resource to college counseling programming. Thus, for those interested in meeting multicultural counseling standards of practice the IACS guidelines provide a starting point.

\section{Conclusion \& Future Directions}

It is hoped that the current recommendations act as a guide to the implementation of multicultural counseling-specific programming to those working in college counseling center settings. There is evidence that MCC training is being taught in higher education (Stebnicki \& Cubero, 2008; Pieterse, Evans, Risner-Butner, Collins, \& Mason, 2009), however, there is a need to improve multicultural training definitions (Cumming-McCann \& Accordino, 2005) that would assist in training applied to counseling center programs. Competent multicultural counseling is a mainstay for centers to provide ethical counseling services. College counseling center experiential learning that adheres to the three factor model (attitudes/beliefs, knowledge, and skills) incorporates a high standard of multicultural counseling training (Arthur \& Achenbach, 2002). College counseling centers strengthen MCC for on-site counselors-in-training when evidence-based evaluation measures for MCC are utilized in conjunction with multiculturally-relevant supervision and training.

Future directions for training within college counseling centers could include case studies and critical incident training (Stebnicki \& Cubero, 2008). Case studies would benefit counselors-in-training by providing more in-depth experiential understanding of what to expect in cross-cultural interactions. Counselors-in-training could then have increased awareness before meeting with clients. Education in critical incidents through site supervision (Toporek, Ortega-Villalobos, \& Pope-Davis, 2004) could increase counselor-in-training knowledge of discrimination encountered by clients from diverse backgrounds. Case studies (Aviles, 2003) and education on critical incidents (Collins \& Pieterse, 2007) are only a couple ways that future training of counselors-in-training can be strengthened. Additional practice guidelines are available (e.g. Roysircar, Sandhu, \& Bibbins, 2003).

Research within college counseling centers that measures the effectiveness of programming in multicultural counseling is needed. The measurement of MCC has benefited from the use of other performance indicators in addition to self-report measures (Cartwright, Daniels, \& Zhang, 2008). Alternative methods to measure MCC such as Constantine's (2001) use of multicultural counselor skill ratings by clinical supervisors and Pope-Davis et al.'s (2002) use of client ratings could strengthen future research. Additionally, future research could explore the impact of college counseling center site supervision on MCC. A significant relationship between higher levels of supervision satisfaction and more perceived MCC has been found. Studies examined supervision factors affecting MCC in terms of racial identity and racial matching between supervisor and counselor-in-training (Ladany, Brittan-Powell, Pannu, 1997), working alliance 
(Ladany, Ellis, \& Friedlander, 1999; Patton \& Kivlighan, 1997), and the effects of critical incidents on supervision (Toporek et al., 2004). The research examples above could promote the applied learning of counselors-in-training practicing in college counseling centers.

Continued professional development of supervisors and counselors-intraining is another way that college counseling center programs can provide the most up-to-date multicultural counseling. New directions include the formation of advocacy to competent multicultural counselor repertoires. Specifically, multiculturalism as a movement has moved into the realm of social justice, where counselors are now encouraged not only to be competent counselors, but effective advocates for people from diverse populations inside and outside of the counseling office (Pieterse et al., 2009).

\section{References}

Arredondo, P. \& Toporek, R. (2004). Multicultural counseling competence = ethical practice. Journal of Mental Health Counseling, 26(1), 44-55.

Arthur, N., \& Achenbach, K. (2002). Developing multicultural counseling competencies through experiential learning. Counselor Education and Supervision, 42, 2-14.

Aviles, R. M. D. (2003). Multicultural issues in assessment: Assessment procedures with a Latina. In G. Roysircar, D. S. Sandhu, \& V. E. Bibbins (Eds.), Multicultural Competencies: A guidebook of practices (pp. 8195). Alexandria, VA: AMCD.

Cartwright, B. Y., Daniels, J., \& Zhang, S. (2008). Assessing multicultural competence: Perceived versus demonstrated performance. Journal of Counseling \& Development, 86, 318-322.

Collins, N. M., \& Pieterse, A. L. (2007). Critical incident analysis based learning: Anapproach to training for active racial and cultural awareness. Journal of Counseling and Development, 85, 14-23.

Constantine, M. G. (2001). Multiculturally-focused counseling supervision: Its relationship to trainees' multicultural counseling self-efficacy. Clinical Supervisor, 20(1), 87-98.

Constantine, M. G., Gloria, A. M., \& Ladany, N. (2002). The factor structure underlying three self-report multicultural counseling competence scales. Cultural Diversity and Ethnic Minority Psychology, 8(4), 334-345.

Constantine, M. G., \& Ladany, N. (2000). Self-report multicultural counseling competence scales: Their relation to social desirability attitudes and multicultural case conceptualization ability. Journal of Counseling Psychology, 47(2), 155-164. 
Council for Accreditation of Counseling and Related Education Programs (CACREP). (2009). 2009 standards. Retrieved on October 27, 2010. www.cacrep.org/soo9standards.doc

Council on Rehabilitation Education (CORE). (2008). Current CORE accreditation standards 10/17/2008. Retrieved on October 27, 2010 www.corerehab.org/NonMan Docs/corestandards.101708.doc

Cubero, C. G. (2009). An investigation of master's level counselor-in-training multicultural counseling skill competence and personality (Doctoral Dissertation). Retrieved from Proquest. (UMI: 3395653).

Cumming-McCann, A. \& Accordino, M. P. (2005). An investigation of rehabilitation counselor characteristics, White racial attitudes, and self-reported multicultural counseling competencies. Rehabilitation Counseling Bulletin, 48(3), 167-176.

D'Andrea, M., Daniels, J., \& Heck, R. (1991). Evaluating the impact of multicultural counseling training. Journal of Counseling and Development, 70, 143-150.

Donnell, C. M. (2008). Examining multicultural counseling competencies of rehabilitation counseling graduate students. Rehabilitation Education, 22, 47-58.

International Association of Counseling Services (IACS). (2010). Standards for university and college counseling services. Alexandria, VA: International Association of Counseling Services, Inc. Retrieved from http:// www.iacsinc.org/lACS\%20Accreditation\%20Standards\%20Approved\% 200ctober\%2020,\%202010.pdf.

Kim, B. S. K., Cartwright, B. Y., Asay, P. A., \& D’Andrea, M. J. (2003). A revision of The Multicultural Awareness, Knowledge, and Skills SurveyCounselor Edition. Measurement and Evaluation in Counseling and Development, 36, 161-180.

Kocarek, C. E., Talbot, D. M., Batka, J. C., \& Anderson, M. Z. (2001). Reliability and validity of three measures of multicultural competency. Journal of Counseling and Development, 79, 486-496.

Ladany, N., Brittan-Powell, C. S., \& Pannu, R. K. (1997). The influence of supervisory racial identity interaction and racial matching on the supervisory working alliance and supervisee multicultural competence. Counselor Education \& Supervision, 36, 284-304. 
Ladany, N., Ellis, M. V., Friedlander, M. L. (1999). The supervisory working alliance, trainee self-efficacy, and satisfaction. Journal of Counseling and Development, 77, 447-455.

Middleton, R. A., Rollins, C. W., Sanderson, P. L., Leung, P., Harley, D. A., Ebener, D., \& Leal-Idrogo, A. (2000). Endorsement of professional multicultural rehabilitation competencies and standards: A call to action. Rehabilitation Counseling Bulletin, 43(4), 219-240.

Miller, G. A. (1985). The Substance Abuse Subtle Screening Inventory (SASSI) Manual. Springville, IN: The SASSI Institute.

Patton, M. J. \& Kivlighan, Jr., D. M. (1997). Relevance of supervisory alliance to the counseling alliance and to treatment adherence in counselor training. Journal of Counseling Psychology, 44(1), 108-115.

Pieterse, A. L., Evans, S. A., Risner-Butner, A., Collins, N. M., \& Mason, L. B. (2009). Multicultural competence and social justice training in counseling psychology and counselor education: A review and analysis of a sample of multicultural course syllabi. The Counseling Psychologist, 37, 93-115.

Ponterotto, J. G., Rieger, B. P., Barrett, A., \& Sparks, R. (1994). Assessing multicultural counseling competence: A review of instrumentation. Journal of Counseling \& Development, 72(3), 316-322.

Pope-Davis, D. B., \& Dings, J. G. (1994). An empirical comparison of two selfreport multicultural counseling competency inventories. Measurement and Evaluation in Counseling and Development, 27(2), 93-102.

Pope-Davis, D. B., Liu, W. M., Toporek, R. L., \& Brittan-Powell, C. S. (2001). What's missing from multicultural competency research: Review, introspection, and recommendations. Cultural Diversity and Ethnic Minority Psychology, 7(2), 121-138.

Pope-Davis, D. B. \& Ottavi, T. M. (1994). Examining the association between self-reported multicultural counseling competencies and demographic variables among counselors. Journal of Counseling \& Development, 72, 651-654.

Pope-Davis, D. B., Toporek, R. L., Ortega-Villalobos, L., Ligiero, D. P., BrittanPowell, C. S., Liu, W. M., Bashshur, M. R., Codrington, J. N., \& Liang, C. T. H. (2002). Client perspectives of multicultural competence: A qualitative examination. Counseling Psychologist, 30, 355-393.

Roysircar, G., Sandhu, D. S., \& Bibbins, V. E. (2003). Multicultural Competencies: A guidebook of practices.Alexandria, VA: AMCD. 
Sodowsky, G. R., Taffe, R. C., Gutkin, T. B., \& Wise, S. L. (1994). Development of the Multicultural Counseling Inventory: A self-report measure of multicultural competencies. Journal of Counseling Psychology, 41(2), 137148.

Stebnicki, M. A. \& Cubero, C. G. (2008). Multicultural counseling in rehabilitation: A content analysis of syllabi from rehabilitation training programs. Rehabilitation Education, 22, 89-100.

Sue, D. W., Bernier, J. B., Durran, M., Feinberg, L., Pederson, P., Smith, E. J., \& Vazquez-Nuttall, E. (1982). Position Paper: Cross-cultural counseling competencies. The Counseling Psychologist, 10(2), 45-52.

Toporek, R. L., Ortega-Villalobos, L., \& Pope-Davis, D. B. (2004). Critical incidents in multicultural supervision: Exploring supervisees' and supervisors' experiences. Journal of Multicultural Counseling and Development, 32, 66-83. 